\title{
NiTi splat features during Vacuum Thermal Spraying onto several substrates
}

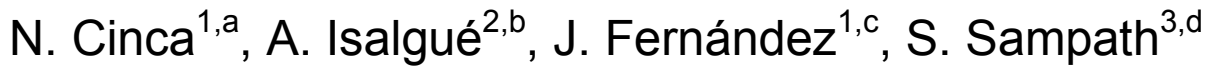 \\ ${ }^{1}$ Centre de Projecció Tèrmica, Fac. Química, Universitat de Barcelona, Diagonal 649 E-08028, \\ Barcelona; Spain \\ ${ }^{2}$ Dep. Física Aplicada, Universitat Politècnica Catalunya, Pla Palau 18 E-08003, Barcelona; Spain \\ ${ }^{3}$ Center for Thermal Spray Research, Stony Brook, New York; USA \\ ancinca@cptub.eu, bantonio.isalgue@upc.edu, cjfernandez@cptub.eu, \\ dssampath@ms.cc.sunysb.edu
}

Keywords: coating; vacuum thermal spray; $\mathrm{NiTi}$, splat.

\begin{abstract}
Vacuum Plasma Spraying (VPS) has been used to produce coatings onto steel substrates. This work deals with the study of splat morphology of the NiTi alloy sprayed by VPS onto different substrates (aluminium, copper, stainless steel, glass and alumina). All the previous characteristics are discussed in terms of wettability and thermal conductivities regarding the rapid cooling involved in the process. Although identical conditions were used during thermal spraying, a wide variety of splat formations were observed; commonly, slushy or splash/disc splats are formed depending on whether the particles have partially or fully melted. The thermal effusivity of the substrate material, which is a measure of its ability to exchange thermal energy with its surroundings, seems to play an important role promoting more or less spreading. The higher the thermal effusivity is, the more rapidly the splats are cooled, thus starting the solidification before they come to rest and, changing their morphology.
\end{abstract}

\section{Introduction}

NiTi alloy coatings have been commonly produced either by means of the magnetron sputtering technique [1-4] or Vacuum Plasma Spraying (VPS) [5-9]. Due to the high reactivity of NiTi alloy with oxygen at high temperatures forming oxides, processes involving high temperatures such as thermal spraying must be performed under vacuum atmospheres. VPS nitinol coatings have low porosity and exhibit interesting properties such as pseudoelasticity [9] and corrosion resistance [10]. Siegman et al. [6] produced free-standing parts by spraying NiTi onto glass and grit-blasted carbon steel substrates resulting in smooth bottom surfaces from those removed from the glass substrate.

Some recent experiments with Cold Gas Spraying (CGS) technique have also produced nonoxidised coatings [11]; such process is thought to be really promising due to its cost-effectiveness but still more studies need to be done with such alloys. The two processes are completely different, within the opposite sites of the thermal spray temperature ranges; cold spray is a solid state process where the spray material is slightly heated, while plasma spray reaches temperatures higher than $3800^{\circ} \mathrm{C}$ leading to molten droplets that result in "splash" or "disc" splats depending on whether the splat solidifies before $\left(T>T_{m}\right)$ or after it has come to rest $\left(T>>T_{m}\right)$ [12]. The splat morphology and therefore the coating microstructure will finally determine the coating properties.

Previous studies on the microstructure of High Velocity Oxy-Fuel (HVOF), Atmospheric Plasma Spray (APS)-quench and VPS nitinol coatings show their different features $[8,13]$, which must be responsible for their differences on adherence values, which are much higher values for vacuum deposits, this is 45,45 and $75 \mathrm{MPa}$ for the three different processes respectively [14]. Adhesive strength to the substrate is especially dependent on splat behavior of individual particles. Therefore, the aim of the present work is to study the splashing behavior of NiTi particles depending on the substrate material. By changing the substrate, the solidification rate of the first layer is mainly affected; therefore coating adherence and phase transitions at the interface can be modified. 


\section{Experimental Procedure}

NiTi powders with austenite phase were manufactured using the gas atomization technique (Fig. 1). The alloy was melted in a $\mathrm{CaO}$ crucible, this is normally preferred instead of other crucible materials such as alumina or magnesia as these contaminates the molten NiTi with oxygen. An $\mathrm{Al}_{2} \mathrm{O}_{3}$ tube coated with $\mathrm{ZrO}_{2}$ was used to plug the hole of the delivery tube fixed at the bottom of the crucible. The melt was atomized under highly pure Ar atmosphere. Traces of oxygen were found in the powder due to some reaction between Ti and the plug tube.

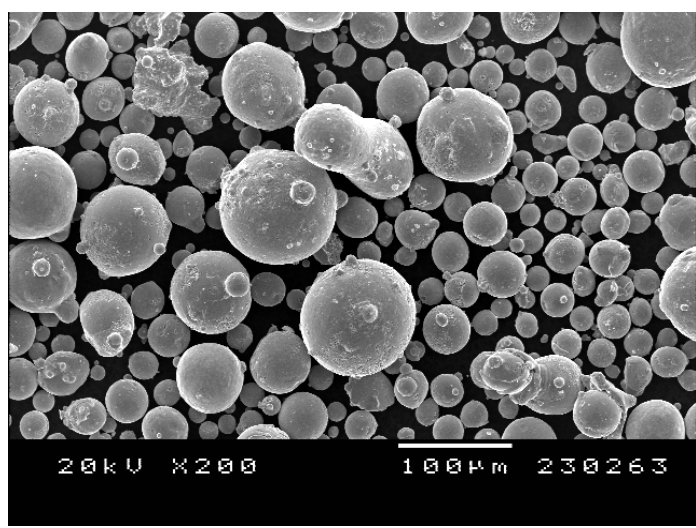

Figure 1. Spherical morphology of the as-atomized Ni-45\%wt.Ti powders.

For the wipe tests, splat runs were performed according to the spraying conditions in Table 1 at $1 \mathrm{~g} / \mathrm{min}$ with a gun transverse speed $10 \mathrm{~mm} / \mathrm{s}$ onto five different substrates, e.g. stainless steel, aluminum, copper, alumina and glass. The metal samples were previously mirror-like polished. The splats were produced using a VPS Plasma System (Sulzer Metco) with F4VB plasma gun and afterwards examined in a Scanning Electron Microscope (JEOL 5310).

Table 1. Thermal spraying parameters for VPS.

\begin{tabular}{|l|l|}
\hline Primary Argon plasma gas flow (L/min) & $45-55$ \\
\hline Secondary Hydrogen plasma gas flow (L/min) & $5-10$ \\
\hline Arc current (A) & 600 \\
\hline Gun voltage (V) & 72 \\
\hline Carrier Argon gas flow (L/min) & $4-5$ \\
\hline Chamber Vacuum Pressure (mbar) & 60 \\
\hline Spraying distance (mm) & 300 \\
\hline
\end{tabular}

\section{Results and Discussion}

"Splash" or star-shaped splat morphologies are observed onto stainless steel and aluminium (Fig. $2 \mathrm{a}, \mathrm{b}$ and $\mathrm{c}$ ), these have a rounded shape with many fingers as result of the starting solidification, especially close to the splat periphery where it is thinner, which may impede the liquid flow and becomes solidified before they come to rest. Such morphologies are also related to poor wetting. More irregular shapes are obtained onto copper (Fig. 2d) and characteristic rims are distinguished (Fig. 2 e). Furthermore, small droplets can be observed on the splats and even on the substrate surface; this may result from the fragmentation of the spreading sheet of liquid [15].

Substrate properties have to be considered when discussing the deposition behavior. In the case of plasma coatings thermal properties are especially important. Mechanical properties such as hardness is not considered to play any role on the splat flattening behavior and therefore splat morphology as it may occur in other processes as High Velocity Air Fuel (HVAF) and Cold Gas Spray [11]. Thermal effusivity, $\mathrm{e}=(\mathrm{k} \rho \mathrm{c})^{1 / 2}$, where $\mathrm{k}$ is the thermal conductivity, $\rho$ is the density and $\mathrm{c}$ is the specific heat, will be considered to discuss about the transient heat flows because the thermal spray deposition is a dynamic process taking place in a very short time. Approximate 
effusivity data can be obtained from literature or from furnishers. Copper is the substrate that has the higher thermal effusivity value, around $3.3 \times 10^{4}$, which will produce higher cooling rates and temperature gradients inside the droplets. These gradients will be the responsible of rims in the droplet since the bottom part of the droplet is not only solidified but also cooled while the upper part is just solidified. On cooling the compressive stresses develop and rims are then formed. Also the high cooling rates will avoid the spread of the molten droplet.

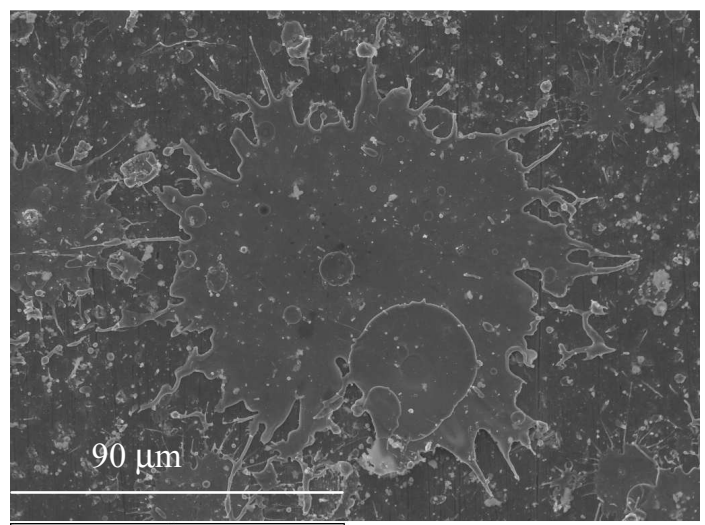

a

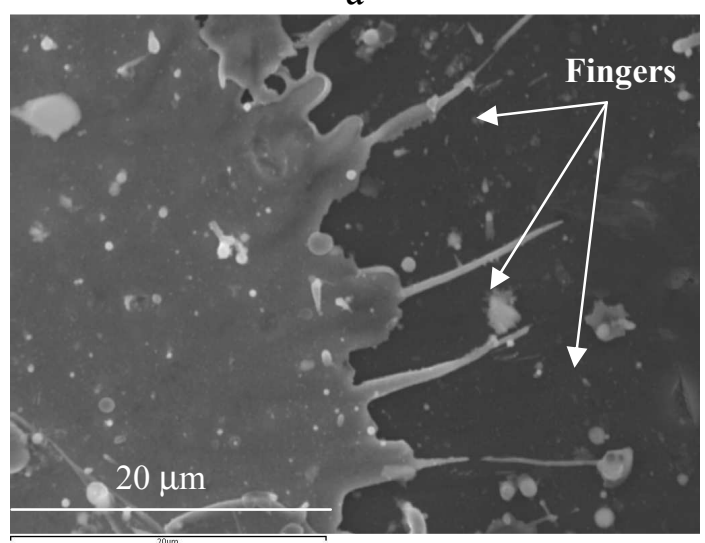

C

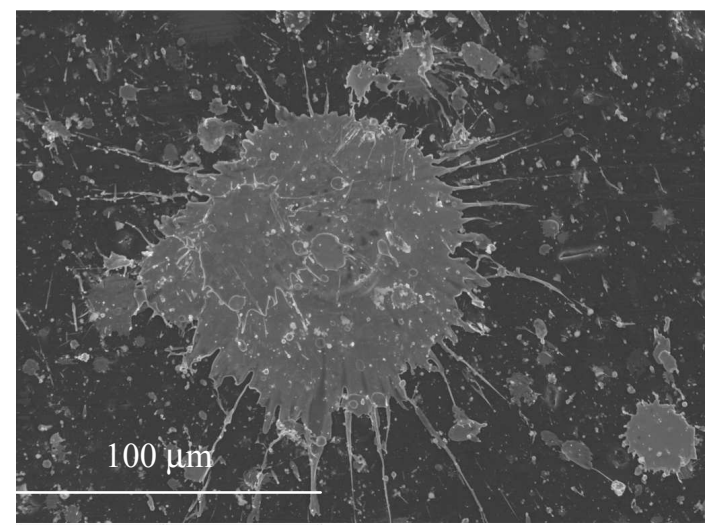

$\mathrm{b}$

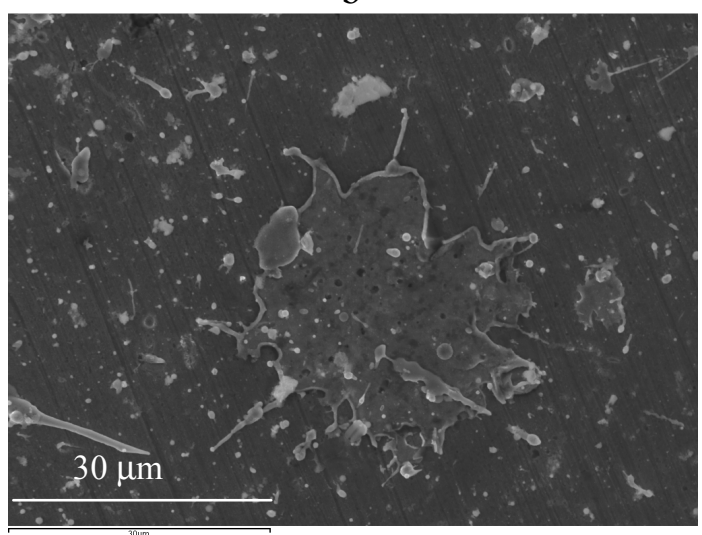

d

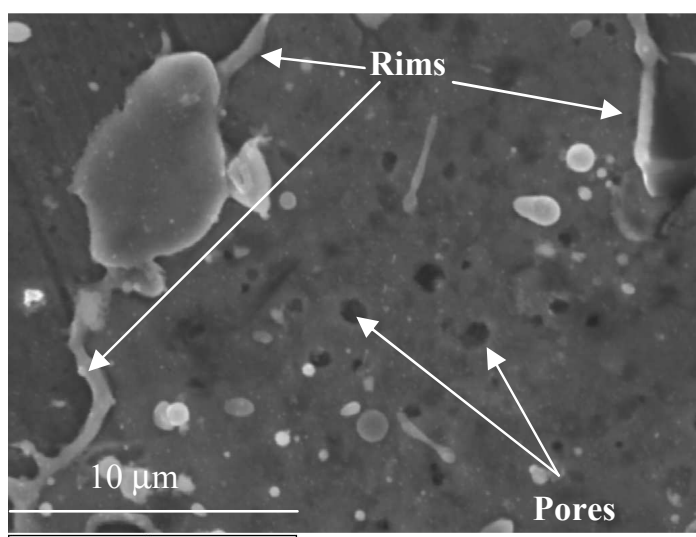

e

Figure 2. Splat morphologies of VPS NiTi powder sprayed onto metal substrates: (a) stainless steel $(b, c)$ aluminium and $(d, e)$ copper.

Splashing is also strongly affected by substrate temperature resulting in quite significant changes of morphologies; substrate temperature affects [16] splat morphology through the change in interface nature, surface chemistry, solidification behavior, wetting and contact of molten droplet with substrate, droplet/substrate mechanical interaction; by spraying under vacuum conditions, the absence of surface oxidation is assumed to reduce splat viscosity and splat-substrate internal friction, therefore producing better spreading of a VPS splat [16]. Some pores are found at the splat- 
substrate interface such as indicated in Figure 2e despite the vacuum conditions; Fukumoto et al. explain the mechanism of such pores, Figure 3 of the reference [17], within a splash splat. Regarding these splat shape changes by modifying substrate temperature ("transition temperatures"), they depend on the splat-substrate system and even particle velocity and size. According to Fukumoto, higher transition temperatures are reached by using higher thermal conductive substrates because of their easiest capacity of splat heat dissipation.

A higher splat viscosity is observed when spraying onto alumina, Figure $3 \mathrm{a}$, than onto glass substrate. Initially, the lower thermal conductivities of alumina and glass substrates lead to higher substrate surface temperatures therefore prolonged cooling times letting splats to spread free. However, when considering the thermal effusivity of $\mathrm{Al}_{2} \mathrm{O}_{3}\left(1 \times 10^{4}\right)$ and glass $\left(1.5 \times 10^{3}\right)$ strong differences can be seen. The effusivity of the alumina is similar to that one of stainless steel $(8 \mathrm{x}$ $\left.10^{3}\right)$. Then, the cooling efficiency of the droplet-interface for alumina is also similar to that one of steel and droplets tend to show similar characteristics. However, when the droplet is deposited on glass, the lower effusivity, allow the droplet to keep the thermal energy and then to still remain in liquid state. However, this attached liquid droplet still has a kinetic energy that can produce the ejection of small droplets that can also be seen in figure $3 \mathrm{~b}$.

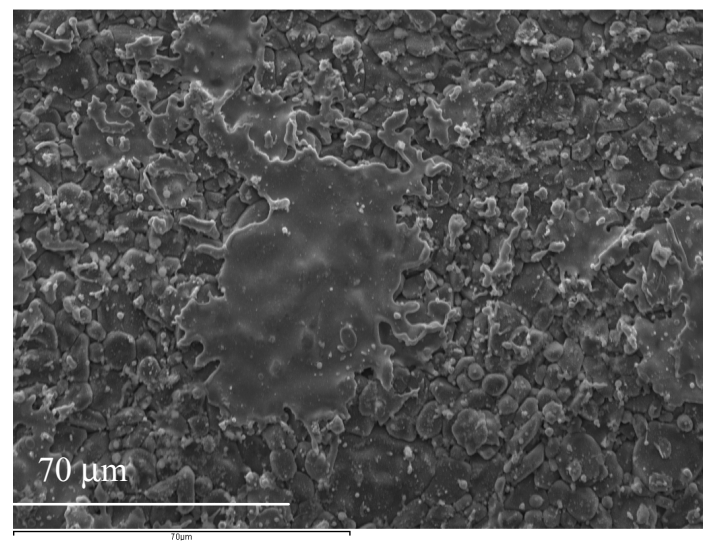

a

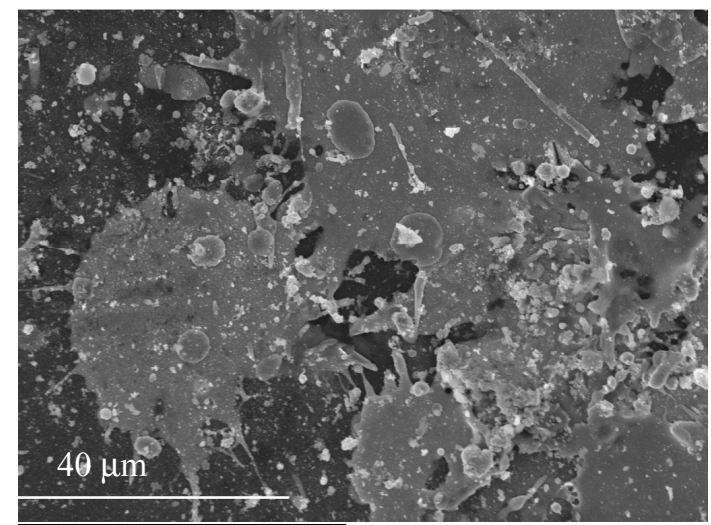

b

Figure 3. Splat morphologies of VPS NiTi powder sprayed onto cercamic substrates: (a) alumina and (b) glass.

\section{Summary}

NiTi splats have been deposited by means of VPS onto different metallic and ceramic substrates. The effect of the substrate onto the splat morphology has been studied. The effusivity is a better parameter to describe the splat morphology of the sprayed powder than thermal conductivity since the deposition process is always dynamic. The deposition onto alumina shows similar droplet morphologies compared to the stainless steel substrate. Better coating depositions will be obtained considering the thermal effusivity value to adapt the industrial spray conditions according to this parameter.

\section{Acknowledgements}

Authors wish to acknowledge the MICINN for financial funding of the project MAT2009-10827.

\section{References}

[1] K. Otuska, C.M. Wayman, Shape Memory Materials, (Ed.), Cambridge University Press, (1998).

[2] K. Ho, G. P. Carman, Sputter deposition of NiTi thin film shape memory alloy using a heated target, Thin Solid Films 370 (2000) 18-29.

[3] Y. Q. Yang, H. S. Jia, Z. F. Zhang, H. M. Shen, A. Hu, Y. N. Wang, Mater Letters 22 (1995) 137-140. 
[4] K. Halter, A. Sickinger, S. Siegmann, L. Zysset, SMST-2003: The International Conference on Shape Memory and Superelastic Technologies; USA; (2004) pp. 163-172.

[5] K. Halter, A. Sickinger, L. Zysset, S. Siegmann, Low pressure wire arc and vacuum plasma spraying of NiTi shape memory alloys, Thermal Spray 2003: Advancing the Science \& Applying the Technology. Ed. C. Moreau and B. Marple. Ohio USA, 589-595.

[6] S. Siegmann, K. Halter, B. Wielage, Vacuum plasma sprayed coatings and freestanding parts of NiTi shape memory alloy. ITSC 2002, pp 357-361.

[7] A. Sickinger, Thermal Spraying of NiTi alloys, SMST-2003: The International Conference on Shape Memory and Superelastic Technologies; USA; (2004) 153-162.

[8] J.M. Guilemany, N. Cinca, S. Dosta, J. Fernandez, Structural Characterization of Intermetallic NiTi Coatings Obtained by Thermal Spray Technologies, Mater Sci Forum, 636-637, (2010), 1084-1090.

[9] H. Nakayama, M. Taya, R.W. Smith, T. Nelson, M. Yu, E. Rosenzweig, Shape memory effect and superelastic behavior of TiNi shape memory alloy processed by vacuum plasma spray method, Mater Sci Eng A, 459, (2007), 52-59.

[10] J. M. Guilemany, N. Cinca, S. Dosta, A.V. Benedetti, Corrosion behaviour of thermal sprayed nitinol coatings, Corr Sci., 51 (2009), 171-180.

[11] S. Tria, O. Elkedim. R. Hamzaoui, X. Guo, F. Bernard, N. Millot, O. Rapaud, Deposition and characterization of cold sprayed nanocrystalline NiTi, Powder Technol, 210, (2011), 181-188.

[12] W. Trompetter, M. Hyland, D. McGrouther, P. Munroe, A. Markwitz, Effect of Substrate Hardness on Splat Morphology in High-Velocity Thermal Spray Coatings, J Thermal Spray Technol. 15:4, (2006), 663-669.

[13] N Cinca, A Isalgué, J Fernández, J M Guilemany, Structure characterization and wear performance of NiTi thermal sprayed coatings, Smart Materials and Structures 19:8 (2010) 9pp.

[14] N. Cinca Luis. Study of the structure-properties relationship of Fe-Al, Nb-Al and Ni-Ti intermetallic coatings obtained by Thermal Spray Technologies, Dissertation (2008).

[15] M. Pasandideh-Fard, V. Pershin, S. Chandra, J. Mostaghimi, Splat Shapes in a Thermal Spray Coating Process: Simulations and Experiments, J Thermal Spray Technol.11:2 (2002) 206-217.

[16] S. Sampath, H. Herman, Rapid Solidification and Microstructure Development during Plasma Spray Deposition, J Thermal Spray Technol. 5:4, (1996), 445-456.

[17] M. Fukumoto, S. Kato, I. Okane, in: A. Ohmori (Ed.), Proceedings of the Integrated Thermal Spray Conference, Kobe, Japan, May 1995, Japan High Temp Soc (1995), 353. 